OPEN ACCESS

Edited by:

Tobias Brosch

University of Geneva, Switzerland

Reviewed by:

Wing-Yee Cheung,

University of Southampton, UK

Lisa Glynn,

Veterans Affairs Puget Sound Health

Care System, USA

${ }^{*}$ Correspondence:

Florian E. Klonek,

Department of

Industrial/Organizational and Social

Psychology, Institute of Psychology,

Technische Universität Braunschweig,

Spielmannstr. 11, 38106

Braunschweig, Germany

f.klonek@tu-bs.de

Specialty section:

This article was submitted to

Personality and Social Psychology, a section of the journal Frontiers in

Psychology

Received: 14 December 2014

Accepted: 19 February 2015

Published: 13 March 2015

Citation:

Klonek FE and Kauffeld S (2015)

Talking with consumers about energy reductions: recommendations from a motivational interviewing perspective.

Front. Psychol. 6:252

doi: 10.3389/fpsyg.2015.00252

\section{Talking with consumers about energy reductions: recommendations from a motivational interviewing perspective}

\author{
Florian E. Klonek ${ }^{*}$ and Simone Kauffeld \\ Department of Industrial/Organizational and Social Psychology, Technische Universität Braunschweig, Braunschweig, \\ Germany
}

Reduction of energy costs has become a concern for many organizations. First, we review energy-saving studies in organizations in which consumers showed resistance to change their behavior. Second, we relate resistance to change to the psycholinguistic construct "sustain talk" that describes verbal arguments against behavior change (e.g., "Work processes have priority here"). Third, we argue how Motivational Interviewing (MI) - an interaction-approach to facilitate behavior change-might be helpful in dealing with this behavior. We transfer Ml to interactions about energy-savings in organizations and demonstrate how qualification in Ml for energy managers may affect these interactions. Therefore, we present three short case scenarios (i.e., video vignettes) that demonstrate socio-interactional mechanisms underlying energy-relevant decisions and behaviors. Consumer' verbal responses are graphed as one single time-variant index of readiness versus resistance (R-index) in order to illustrate interactional dynamics. In sum, we combine theoretical and empirical perspectives from multiple disciplines and discuss an innovative socio-interaction approach that may facilitate energy-efficient behavior in organizations.

Keywords: change intervention, change talk, energy-saving, interaction analysis, motivational interviewing, MI Skill Code, resistance to change, $R$-index

Reducing the impact of rising energy costs has increasingly become a concern for many organizations (Garabuau-Moussaoui, 2014; Leyge, 2014; Morgenstern, 2014; Tharan, 2014). Whereas the engineering field has developed mostly technical measures to increase energy efficiency, there is an increasing trend to recognize that the behavior of consumers who actually work in the organizations is equally important (Kraft and Neubeck, 2004; Carrico and Riemer, 2011; Janda, 2011; Steiner et al., 2011; Kauran, 2013; Cowan, 2014; Parkes, 2014; Schäfer, 2014). However, recent studies that aim to reduce energy behavior have also reported that consumers show resistance to changing their energy consumption at work (Griesel, 2004; Kaplowitz et al., 2012; Murtagh et al., 2013).

In order to facilitate interactions with consumers about energy-relevant decisions, this perspective paper offers the following contributions. First, we give a brief overview of organizational studies that reported consumer resistance when energy-relevant behaviors were in need of change. Second, we relate resistance to change to the psycholinguistic constructs of change language (i.e., change talk vs. sustain talk) and hypothesize that language is an active ingredient in fostering behavior change. Third, we propose Motivational Interviewing (MI) to be a social interaction-based approach that may help energy managers to promote energy-saving behaviors in organizations. We draw on empirical evidence in the field of clinical psychology (e.g., Magill et al., 2014) in order to hypothesize how interactional mechanisms could affect energy-relevant behavior. Fourth, we produced 
demonstration material that highlights how MI-based approaches could be applied in the context of energy-saving interventions. Fifth, we visualize interactional dynamics with a newly developed temporal measure of readiness and resistance to change by means of three video vignettes. Human resources and training departments in organizations can use these vignettes for training purposes.

\section{Behavior-Based Energy-Saving Interventions and Resistance to Change}

Organizations are increasingly trying to save energy either for economic purposes or to accomplish a reduction of carbon emissions (Homburg, 2004; D’Mello et al., 2011; DuBois et al., 2013). Whereas one energy-efficiency approach includes technical improvements, such as increased heat insulation or replacing ventilation with volume flows (Lutzenhiser, 1993), technical engineers are realizing that the behavior of people who work in organizations also contributes to energy consumptions (Janda, 2011). Science laboratories in universities have one of the highest energy usages and offer high potential to implement behavior-based energy-conservation procedures with consumers (Kaplowitz et al., 2012). Kaplowitz et al. interviewed 59 participants (principal investigators, lab staff, and student researchers) about possibilities to adapt energy-conserving behavior at work. Despite a favorable attitude toward energy-saving behaviors, participants argued that operational, economic, and work-related barriers hindered them from saving energy. In a study from Griesel (2004), the author conducted a workshop with university staff to promote energy-efficient behavior. She reported that some of the proposed measures (e.g., switching off laptop computers during breaks) were considered unacceptable by participants.

Murtagh et al. (2013) reported similar problems in an energysaving intervention study. The authors implemented a monitoring device in a university office building that displayed employees their current energy use. Unfortunately, $41 \%$ of the participants did not even register for the feedback device. The authors also held focus groups about their office energy use and reported that participants showed a "syndrome of reasoning" (Murtagh et al., 2013, p. 724) - a term for describing verbal responses or selfdefense for not saving energy (e.g., inconvenience, technical reasons/myths, social norms, automation, work demands, savings are too small, etc...).

Altogether, observations from these organizational studies suggest that the language of consumers seems to be indicative of their respective motivation. Participants who are not motivated to take further actions will also express this verbally. In fact, verbal behavior ("I will not do this") is a powerful means to express resistance toward change measures (Klonek et al., 2014). More recent methodological work has proposed measuring participants' readiness or resistance ${ }^{1}$ in interactions about behavior change in terms of change talk versus sustain talk (Moyers

\footnotetext{
${ }^{1}$ Please note that the terms resistance and sustain talk are not interchangeable terms. Typically, current MI theory distinguishes between resistance and sustain talk. Resistance is "interpersonal behavior that reflects dissonance in the working relationship [whereas] sustain talk does not in itself constitute discord" (Miller and Rollnick, 2013, p. 408). Resistance is necessarily interpersonal (i.e., not residing
}

et al., 2007; Miller and Johnson, 2008; Gaume et al., 2010; Magill et al., 2010; Klonek et al., 2014; Lombardi et al., 2014; Paulsen et al., 2015). Change talk includes statements that express consumers' readiness to adopt energy-saving routines, such as reasons ("Energy waste is related to increased department costs"), desires ("We do not want to waste energy here"), or needs to change ("It is prohibited by security management to open the windows at night"). By contrast, sustain talk comprises language that speaks against energy-saving measures, such as resistance, reasons to sustain the status quo, a lack of abilities ("I do not know how to operate the heating system-therefore, I don't change it"), or lack of commitment ("I won't promise that I will always think about switching off the lights"). Furthermore, change and sustain talk can be regarded as driving and hindering forces that may determine consumers' energy-related behaviors (Klonek et al., under revision).

This language-based view takes into account that consumers usually express ambivalence rather than sole resistance toward change measures ("Yes, energy savings are important, but it impedes my work flow to shut down the computer during breaks"; Piderit, 2000; Arkowitz, 2002; Klonek et al., 2014). In this view, one part of the statement argues in favor of change, whereas the other part argues against change. These conflicting values are like opposite sides of a decisional balance (Janis and Mann, 1977; Klonek et al., under revision) that are dynamically tipping from one side (sustaining behavior) to the other (changing behavior). So what can organizations do in order to increase the weight of the decisional balance so that consumers move toward saving energy?

One social interaction-based approach that makes use of an individual's ambivalence toward change is a method called MI. It is a communication-based approach that has received large support by numerous meta-analyses as an evidence-based intervention in the helping professions (Hettema et al., 2005; Rubak et al., 2005; Lundahl et al., 2010; Magill et al., 2014). We will briefly present the basic tenets of MI and argue how energy managers in organizations could benefit from MI training.

\section{What is Motivational Interviewing and how Might it Improve Interactions about Energy Behavior?}

MI can be considered as a social interaction-based approach that combines a humanistic mindset with verbal micro-techniques. Technically, it is defined as a

"collaborative, goal-oriented style of communication with particular attention to the language of change. It is designed to strengthen personal motivation for and commitment to a specific goal by eliciting and exploring the person's own reasons for change within an atmosphere of acceptance and compassion." (Miller and Rollnick, 2013, p. 29).

within the person) and specifically different from sustain talk. As organizational researchers are more familiar with the term "resistance to change," we use this term in order to connect it with recent conceptions of socio-interactional dynamics in behavior change. 
MI shares some common ground with participatory energysaving interventions (e.g., consumer-centered formats, such as workshops; Matthies, 2000; Griesel, 2004) and commitmentbuilding strategies (Lokhorst et al., 2013) that have been proposed to be effective in promoting sustainable behavior change. However, MI significantly contributes to these approaches because it gives clear recommendations for how to deal with resistance and how to increase intrinsic motivation. For example, one of the MI principles is to work out discrepancies in a collaborative way: These discrepancies can encompass, for example, energywasting behaviors that are at odds with specific values of the consumer (e.g., "economizing resources" or "being a role-model"). An MI approach advocates that energy-saving procedures should not be enforced top-down from the organization, but rather that consumers' intrinsic motivation has to be developed bottom-up. MI also adds a goal-oriented component in the interaction by reinforcing consumers' own argumentation to save energy, in essence, tipping the decisional balance toward a specific target behavior (i.e., saving energy).

Traditionally, MI is taught within the helping professions, for example, among therapists, counselors, physicians, or nurses (Madson et al., 2009; Forsberg et al., 2010; de Roten et al., 2013). More recent studies have provided evidence that MI is also teachable to non-helping professions, e.g., for engineers (Klonek and Kauffeld, in press) or for environmental inspectors (Forsberg et al., 2014). Whereas MI has not been used in organizations in order to reduce energy-related behavior at work, it has great promise of equipping energy managers successfully with the right mindset and verbal skills in order to discuss these matters.

\section{Demonstration of MI: The Energy Manager as a Social Change Agent}

In order to showcase the use of $\mathrm{MI}$ as a communication method for energy managers, we developed three vignettes (i.e., scripted audio and video material) in which an energy manager discusses energy-efficient behavior with an employee. The development of this material was guided by a multi-step procedure in which we integrated interaction material from two different sources.

First, we used three existing interaction scenarios that systematically varied in terms of MI consistency (Project MILES, 2011) ${ }^{2}$. These scenarios were developed independently from a German MI expert who is also a member of the Motivational Interviewing Network of Trainers (2008). Transcripts were also annotated previously with a coding instrument that classifies verbal behaviors in MI (Martin et al., 2005; Hannöver et al., 2013). As the content of these interactions was not related to energy-saving behavior (i.e., the conversations covered the reduction of smoking behavior), we only used the structure of the behavioral dynamics and replaced the content with arguments that are characteristic of energy-related interactions.

The second source of data included videotaped interactions in which energy advisors discussed energy-reduction mea-

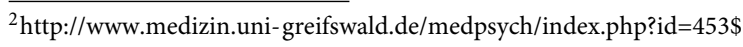

sures with consumers in non-residential buildings (cf. Klonek et al., 2014, submitted). These videotapes served to provide typical arguments that are provided within energy-related interactions (e.g., replacement of several refrigerators with a single one).

Material from both sources was combined systematically in an iterative process and resulted in three vignettes about energy reductions at work (see supplementary audio online material, "Audio 1-3" for English conversations; "Audio 4-6" for German conversations). Table 1 shows the first seven turn takes for each scenario. We kept the content of each conversation similar but varied the interactional dynamics in each conversation in order to illustrate how subtle micro-behaviors may influence the course of an interaction (i.e., the subsequent response of the conversational partner). The mechanisms of interpersonal dynamics were based on theoretical assumptions (i.e., technical hypotheses) and empirical support from MI research (Magill et al., 2014): The main assumption of the technical hypothesis is that MI inconsistent behaviors are positively associated with sustain talk (e.g., Apodaca and Longabaugh, 2009; Klonek et al., 2014) and negatively associated with change talk (e.g., Gaume et al., 2010), whereas MI consistent behaviors make change talk more likely and sustain talk less likely (e.g., Moyers et al., 2007). With respect to conversations about energy-reductions at work, the technical hypothesis implies that energy managers who are trained in MI verbal skills (Energy Manager B; Audio 2 and 4) will likely increase employees change talk. In contrast, energy managers that have not acquired verbal skills in MI (Energy Manager C; Audio 3 and 6) will also use more MI inconsistent behaviors in conversations to reduce energy and therewith decrease change talk and/or increase sustain talk, respectively.

\section{A Closer Look at Verbal Sequences in Energy-Related Consumer Interactions with the MI Skill Code}

In a second step, we used the MI Skill Code (MISC; Miller et al., 2008) in order to shed light on the interactional dynamics of these conversations. The MISC is an observational coding instrument to assess MI specific verbal skills (for the German version, MISC- $\mathrm{d}^{3}$ : Klonek and Kauffeld, 2012). It defines three behavioral macro-categories for interviewer behaviors (i.e., energy manager) that are either consistent, inconsistent, or neutral to an MI approach. Along the same line, the MISC also defines three macro-categories for the interaction partner (i.e., consumer) that describe their verbal response in terms of change talk, sustain talk, or follow neutral (i.e., no relation to the change topic). Finally, all behavioral macro-categories can be classified into more fine-grained behaviors: For example, open questions, affirmations, emphasizing control, or giving support are all consistent with $\mathrm{MI}$, whereas warnings and confrontations are inconsistent with MI (a full overview of all 34 codes of the MISC is given

\footnotetext{
${ }^{3}$ The MISC-d also includes information on software-support, observer training material, data checking-routines, and use of neutral terms for interaction partners to make the instrument transferable to energy-saving conversations.
} 
TABLE 1 | Comparison of the first seven turn-takes from the three demonstration interactions about energy-saving behavior at work (fully coded transcripts of all scenarios are provided as online material).

\begin{tabular}{|c|c|c|c|c|}
\hline \multirow[t]{2}{*}{ Event } & \multirow[t]{2}{*}{ Speaker } & \multicolumn{3}{|c|}{ Scenario A-C } \\
\hline & & Energy manager A & Energy manager B & Energy manager $\mathbf{C}$ \\
\hline 1 & Energy manager & \multicolumn{3}{|c|}{ Today, I would like to talk with you about possibilities to save energy. [Structure] } \\
\hline 2 & Employee & \multicolumn{3}{|c|}{ Okay. [Follow Neutral] } \\
\hline 3 & Energy manager & \multicolumn{3}{|c|}{ You work in a laboratory. There are some options that will certainly allow you to save energy. [Giving Information] } \\
\hline 4 & Employee & $\begin{array}{l}\text { [I not only work in a laboratory, but I also } \\
\text { work in an office.] [Follow Neutral] } \\
\text { [There are certainly some options to save } \\
\text { energy.] [Change Talk-Other] } \\
\text { [These so-called "options" are always } \\
\text { connected to large expenditures.] } \\
\text { [Sustain Talk-Reason] }\end{array}$ & $\begin{array}{l}\text { [I not only work in a laboratory, but I also } \\
\text { work in an office.] [Follow Neutral] } \\
\text { [There are certainly some options to save } \\
\text { energy.] [Change Talk-Other] [However, } \\
\text { these so-called "options" are always } \\
\text { connected to large expenditures.] } \\
\text { [Sustain Talk-Reason] }\end{array}$ & $\begin{array}{l}\text { [I not only work in a laboratory, but I also } \\
\text { work in an office.] [Follow Neutral] } \\
\text { [These so-called "options" are always } \\
\text { connected to large expenditures.] [Sustain } \\
\text { Talk-Reason] }\end{array}$ \\
\hline 5 & Energy manager & $\begin{array}{l}\text { Don't be so rash. [Confrontation] First off, } \\
\text { we should speak about the methods you } \\
\text { already use to save energy. [Structure] Can } \\
\text { you think of some?" [Closed Question] }\end{array}$ & $\begin{array}{l}\text { First we should perhaps talk about where } \\
\text { you already save energy. [Structure] What } \\
\text { do you do already to save enery? } \\
\text { [Open Question] }\end{array}$ & $\begin{array}{l}\text { Don't be so rash. [Confrontation] First off, } \\
\text { we should speak about the methods you } \\
\text { already use to save energy. [Structure] Can } \\
\text { you think of some? [Closed Question] }\end{array}$ \\
\hline 6 & Employee & $\begin{array}{l}\text { [Well, for example, I have set up my PC } \\
\text { with a coupler strip so that it is not running } \\
\text { on standby the entire time.] [Change } \\
\text { Talk-Taking Steps] [But if I am in a hurry in } \\
\text { the evenings, I don't always remember to } \\
\text { do this.] [Sustain Talk-Taking Steps] }\end{array}$ & $\begin{array}{l}\text { [Well, I always turn on my PC using a } \\
\text { coupler strip so that it is not always running } \\
\text { on standby.] [Change Talk-Taking Steps] } \\
\text { [But in the evenings if I am rushed before } \\
\text { quitting time, I don't always do this.] } \\
\text { [Sustain Talk-Taking Steps] }\end{array}$ & $\begin{array}{l}\text { [Well, for example, I have set up my PC } \\
\text { with a coupler strip so that it is not running } \\
\text { on standby the entire time.] [Change } \\
\text { Talk-Taking Steps] [But if I am in a hurry in } \\
\text { the evenings, I don't always remember to } \\
\text { do this.] [Sustain Talk-Taking Steps] }\end{array}$ \\
\hline 7 & Energy manager & $\begin{array}{l}\text { So it's not so important to you to save } \\
\text { energy in this way. I mean, it is a hand } \\
\text { movement - then the switch is turned off. } \\
\text { [Confrontation] }\end{array}$ & $\begin{array}{l}\text { So often in the past you have switched } \\
\text { the PC completely off, so that it does } \\
\text { not run on Standby. Occasionally, } \\
\text { though, you are in too much of a hurry } \\
\text { and this is not consistently done. } \\
\text { [Complex Reflection] }\end{array}$ & $\begin{array}{l}\text { So it's not so important to you to save } \\
\text { energy in this way. I mean, it is merely a } \\
\text { hand movement - then the switch is turned } \\
\text { off. That is really no big deal! } \\
\text { [Confrontation] }\end{array}$ \\
\hline
\end{tabular}

Bold = highlights important differences in verbal behavior of the energy manager

in the manuals). Altogether, the MISC can be used for annotating conversational dynamics for process researchers (e.g., Moyers et al., 2007). We coded the verbal behaviors between the energy manager and the employee (all coded transcripts, i.e., the Energy Manager A-C, are provided as supplementary online material; "Data Sheet 1-3" for English transcripts; "Data Sheet 4-6" for German transcripts). Table 1 shows the MISC codings for the first seven speaker turns in each scenario. It aims to illustrate how subtle micro-changes within a conversation could influence the motivational response of the conversational partner.

The energy managers start to differ in their verbal behavior in the fifth event of each scenario (cf. Table 1). For example, energy manager $\mathrm{B}$ uses an open question instead of a closed question. The assumption in MI is that open questions are personcentered verbal techniques that invite the interaction partner to disclose more information. In this case, the manager asked the employee about her past behaviors to save energy. The question is evocative because it stimulates the employee to discover potential discrepancies between behaviors at home vs. at work.

In the seventh event, the manager in scenario B uses a complex reflection-MI consistent behavior-whereas the managers in scenarios $\mathrm{A}$ and $\mathrm{C}$ confront the employee. Confrontations are MI inconsistent "expert-like responses that have a particular negative-parent quality" (Miller et al., 2008, p. 11). They restrict the autonomy of the employee and can even arouse reactance (Klonek et al., 2014). By contrast, complex reflections are person-centered techniques that repeat or paraphrase statements of the employee, but can also add meaning to it. Reflections are active listening statements in which the energy manager tries to understand the problems of the employee in implementing energy-saving routines. This can positively influence the relationship between conversational partners. Furthermore, reflections help the conversational partner to listen to their own statements (i.e., reflecting as a form of verbal mirroring) and selectively stress their change talk to direct the interaction toward the change target (Barnett et al., 2014).

\section{Capturing Change-Related Dynamics with Consumers: The R-Index}

In the previous section, we have described some microinteractional dynamics using the MISC (e.g., MI inconsistent 


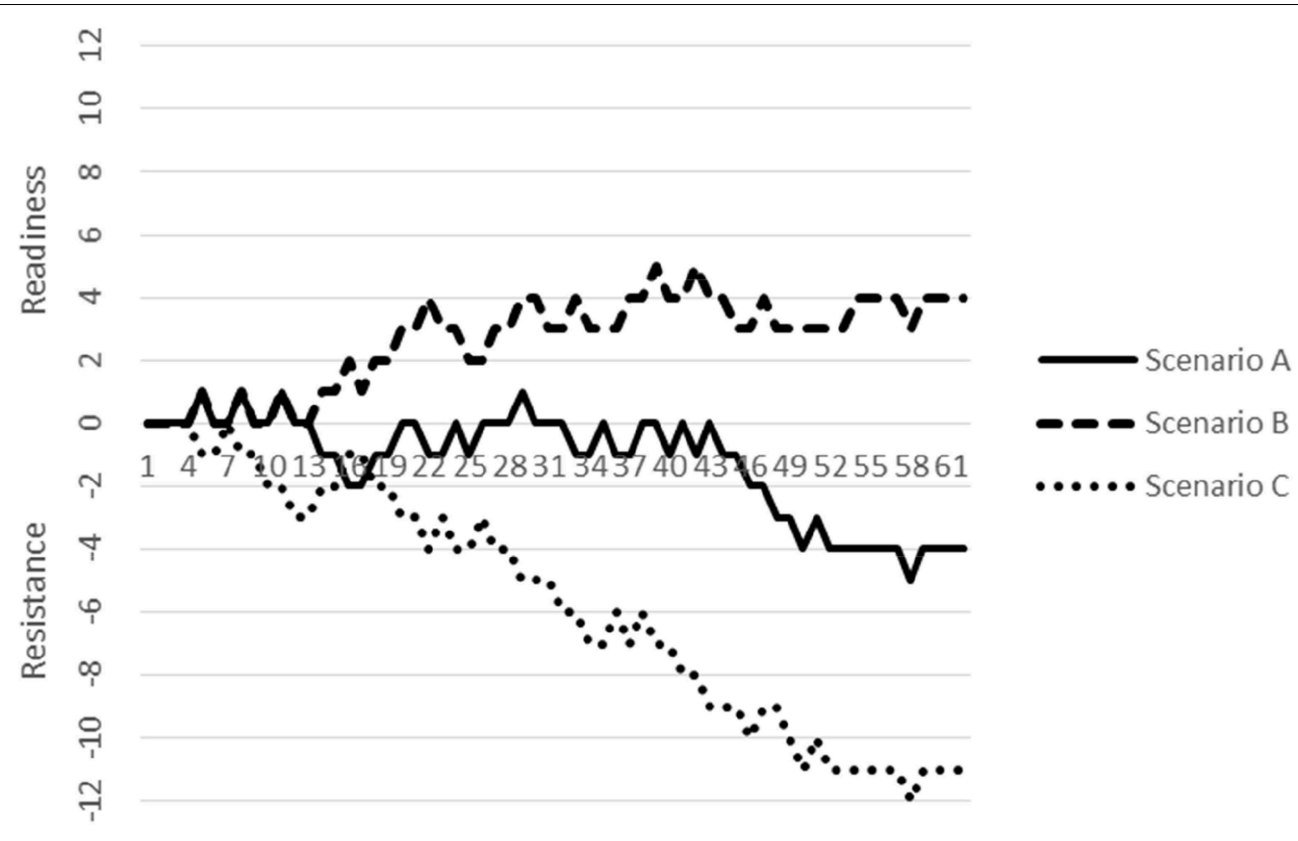

FIGURE 1 | Interactional dynamics graphed with the R-index (Readiness/Resistance) for the three demonstration scenarios on energy-saving behavior at work. Note. The $x$-axis shows the number of events (i.e., parsed thought units or utterances).

behavior, followed by sustain talk). Whereas this perspective helps energy managers to reflect on their verbal behaviors, we also want to show how to capture the readiness of consumers on a broader interaction scale. As noted above, the MISC defines verbal responses of conversational partners in terms of change talk, sustain talk, and follow neutral. Recent MI process research suggests using composite scores of change and sustain talk as a "single measure of motivational balance" (Magill et al., 2014, p. 7). Therefore, we developed a mathematical function that transforms these verbal codes into a single-index of readiness and resistance: The R-index (a full description is given in Klonek et al., under revision). Basically, change talk is transformed into a positive integer $(+1)$, whereas sustain talk is transformed into a negative integer $(-1)$, and follow neutral is transformed into zero (0). As the verbal behavior of the conversational partner unfolds over time, it creates a repeated measurement of change talk $(+1)$ and sustain talk $(-1)$ utterances. One of the basic idea in $\mathrm{MI}$ is that conversational partners can talk themselves into the target behavior (e.g., saving energy) by increasing their own change talk. Therefore, the sequence of verbal responses is cumulated from the beginning until the end of the interaction. This summation results in a time-variant index that can show readiness to change (positive slope) versus resistance to change (negative slope). We have produced R-curves for all three vignettes $(\mathrm{A}-\mathrm{C})$ as an interactive video demonstration (see video material in the supplementary online material, "Video 1-3" for English videos; "Video 4-6" for German videos). Figure 1 depicts how the readiness of the employee increases stepwise in scenario B. As noted above, energy manager B used verbal techniques that are characteristic for MI. By contrast, the $\mathrm{R}$-index in scenario $\mathrm{C}$ indicates strong employee resistance. Equally, energy manager $\mathrm{C}$ showed behaviors that are inconsistent with an MI approach, such as confronting, blaming, and restricting autonomy of the employee. In scenario A, the Rindex fluctuates between positive and negative values, that is, the employee showed ambivalence toward change. In this scenario, energy manager A showed both MI consistent and inconsistent behaviors.

All vignettes (coded transcripts, audio files, and videos showing the R-index) can be used for sensitizing practitioners for interactional dynamics in energy-related conversations or as MI training material. Furthermore, future studies can use this training material to investigate whether MI can help organizations to reduce energy consumption in organizations.

\section{Conclusion}

The current perspective integrated the expertise of different disciplines, that is, clinical psychology, change management, communications, and behavioral sciences. We presented a MIbased socio-interactional approach that may positively influence energy-relevant decisions in organizations by means of its person-centered and directive approach. By creating roleplayed vignettes based on recent empirical meta-analyses about MI in clinical process studies (Magill et al., 2014), we illustrated how MI-consistent and MI-inconsistent employer behaviors could theoretically affect consumer responses in the context of energy-related behavior change discussions. We introduced an observational coding scheme (the MI Skill Code) as a means to investigate behavior change interactions. Finally, we created video vignettes of the coded material in which we summarized the complex coding system into one single index of consumer readiness within an energy-related conversation. This material 
can be used for sensitizing energy managers and change agents for interpersonal dynamics in behavior change and for future energy-saving studies that aim to use MI.

\section{Acknowledgments}

The development of this material was supported by the German Federal Ministry of Economics and Technology (BMWi)

\section{References}

Apodaca, T. R., and Longabaugh, R. (2009). Mechanisms of change in motivational interviewing: a review and preliminary evaluation of the evidence. Addiction 104, 705-715. doi: 10.1111/j.1360-0443.2009.02527.x

Arkowitz, H. (2002). Toward an integrative perspective on resistance to change. J. Clin. Psychol. 58, 219-227. doi: 10.1002/jclp.1145

Barnett, E., Spruijt-Metz, D., Moyers, T. B., Smith, C., Rohrbach, L. A., Sun, P., et al. (2014). Bidirectional relationships between client and counselor speech: the importance of reframing. Psychol. Addict. Behav. 28, 1212-1219. doi: 10.1037/ a0036227

Carrico, A. R., and Riemer, M. (2011). Motivating energy conservation in the workplace: an evaluation of the use of group-level feedback and peer education. J. Environ. Psychol. 31, 1-13. doi: 10.1016/j.jenvp.2010.11.004

Cowan, K. (2014). "Energy steward turn off the lights or 1000 little steps," in European Conference on Behaviour and Energy Efficiency (Oxford, $\mathrm{UK})$

D’Mello, S., Ones, D. S., Klein, R. M., Wiernik, B. M., and Dilchert, S. (2011). "Green company rankings and reporting of pre-environmental efforts in organizations, in Poster session presented at the Annual Conference of the Society for Industrial and Organizational Psychology (Chicago, IL).

de Roten, Y., Zimmermann, G., Ortega, D., and Despland, J. N. (2013). Metaanalysis of the effects of MI training on clinicians' behavior. J. Subst. Abuse Treat. 45, 155-162. doi: 10.1016/j.jsat.2013.02.006

DuBois, C. L., Astakhova, M. N., and DuBois, D. A. (2013). "Motivating behavior change to support organizational environmental sustainability goals," in Green Organizations: Driving change with IO psychology, eds A. H. Huffman and S. R. Klein (New York, NY: Routledge), 186-207.

Forsberg, L., Forsberg, L. G., Lindqvist, H., and Helgason, A. R. (2010). Research Clinician acquisition and retention of Motivational Interviewing skills: a twoand-a-half-year exploratory study. Subst. Abuse Treat. Prevent. Policy, 5, 1-14. doi: 10.1186/1747-597X-5-8

Forsberg, L., Wickström, H., and Källmén, H. (2014). Motivational interviewing may facilitate professional interactions with inspectees during environmental inspections and enforcement conversations. PeerJ 2:e508. doi: $10.7717 /$ peerj. 508

Garabuau-Moussaoui, I. (2014). "How people work and live in energy-efficient workplaces? logics of actions, social tensions and actual issues of occupants in energy-efficient office buildings," in European Conference on Behavior and Energy Efficiency (Oxford, UK).

Gaume, J., Bertholet, N., Faouzi, M., Gmel, G., and Daeppen, J. B. (2010). Counselor motivational interviewing skills and young adult change talk articulation during brief motivational interventions. J. Subst. Abuse Treat. 39, 272-281. doi: 10.1016/j.jsat.2010.06.010

Griesel, C. (2004). Nachhaltigkeit im Bürokontext - eine partizipative Intervention zur optimierten Stromnutzung [Sustainability in organizational context - a participatory intervention to optimize energy user behavior]. Umweltpsychologie 8, $30-48$.

Hannöver, W., Blaut, C., Kniehase, C., Martin, T., and Hannich, H. J. (2013). Interobserver agreement of the German translation of the motivational interviewing sequential code for observing process exchanges (MI-SCOPE; D). Psychol. Addict. Behav. 27, 1196-1200. doi: 10.1037/a0033041

Hettema, J., Steele, J., and Miller, W. R. (2005). Motivational interviewing. Annu. Rev. Clin. Psychol. 1, 91-111. doi: 10.1146/annurev.clinpsy.1.102803. 143833 through Grant 03ET1004B (Project EnEff Campus: blueMAP TU Braunschweig).

\section{Supplementary Material}

The Supplementary Material for this article can be found online at: http://www.frontiersin.org/journal/10.3389/fpsyg.2015.00252/ abstract

Homburg, A. (2004). Environmental actions in enterprises: a survey of influential factors and formation approaches from a social and environmental psychological perspective. Umweltpsychologie 8, 56-78.

Janda, K. B. (2011). Buildings don't use energy: people do. Archit. Sci. Rev. 54, 15-22. doi: 10.3763/asre.2009.0050

Janis, I. L., and Mann, L. (1977). Decision Making: A Psychological Analysis of Conflict, Choice, and Commitment. New York, NY: Free Press.

Kaplowitz, M. D., Thorp, L., Coleman, K., and Kwame Yeboah, F. (2012). Energy conservation attitudes, knowledge, and behaviors in science laboratories. Energy Policy 50, 581-591. doi: 10.1016/j.enpol.2012.07.060

Kauran, K. (2013). Motivation of Energy-Users is Crucial! Re-Co Newsletter 2013, 2, 5. Available online at: http://www.re-co.eu/sites/ default/files/files/Re_Co_Newsletter_No2.pdf

Klonek, F. E., and Kauffeld, S. (2012). Der Motivational Interviewing Skill Code, deutsche Version (2.3). [The motivational interviewing skill code, German version (2.3)]. Unpublished manual, Technische Universität Braunschweig. Available online at: https://www.tu-braunschweig.de/Medien-DB/aos/hinterlegtepdfs/misc-d.pdf

Klonek, F. E., and Kauffeld, S. (in press). Providing Engineers with OARS and EARS: Effects of a Skills-Based Vocational Training in Motivational Interviewing for Engineers in Higher Education. Higher Education, Skills and Work-Based Learning.

Klonek, F. E., Lehmann-Willenbrock, N., and Kauffeld, S. (2014). Dynamics of resistance to change: a sequential analysis of change agents in action. J. Change Manag. 14, 334-360. doi: 10.1080/14697017.2014.896392

Kraft, D., and Neubeck, S. (2004). Approaches of internal environmental communication within the scope of environmental management at Volkswagen Nutzfahrzeuge (VWN) Hannover. Umweltpsychologie 8, 42-55. doi: $10.1037 / \mathrm{a} 0036227$

Leyge, C. (2014). “Saving energy in the workplace: why, and for whom?” Presented at the European Conference on Behaviour and Energy Efficiency, (Oxford, UK).

Lokhorst, A. M., Werner, C., Staats, H., van Dijk, E., and Gale, J. L. (2013). Commitment and behavior change: a meta-analysis and critical review of commitmentmaking strategies in environmental research. Environ. Behav. 45, 3-34. doi: 10.1177/0013916511411477

Lombardi, D. R., Button, M. L., and Westra, H. A. (2014). Measuring motivation: change talk and counter-change talk in cognitive behavioral therapy for generalized anxiety. Cogn. Behav. Therapy 43, 12-21. doi: 10.1080/16506073.2013.846400

Lundahl, B. W., Kunz, C., Brownell, C., Tollefson, D. S., and Burke, B. (2010). A meta-analysis of motivational interviewing: twenty-five years of empirical studies. Res. Social Work Prac. 20, 137-160. doi: 10.1177/1049731509347850

Lutzenhiser, L. (1993). Social and behavioral aspects of energy use. Annu. Rev. Energy Environ. 18, 247-289. doi: 10.1146/annurev.eg.18.110193.001335

Madson, M. B., Loignon, A. C., and Lane, C. (2009). Training in motivational interviewing: A systematic review. J. Subst. Abuse Treat. 36, 101-109. doi: 10.1016/j.jsat.2008.05.005

Magill, M., Apodaca, T. R., Barnett, N. P., and Monti, P. M. (2010). The route to change: within-session predictors of change plan completion in a motivational interview. J. Subst. Abuse Treat. 38, 299-305. doi: 10.1016/j.jsat.2009. 12.001

Magill, M., Gaume, J., Apodaca, T. R., Walthers, J., Mastroleo, N. R., Borsari, B., et al. (2014). The technical hypothesis of motivational interviewing: a metaanalysis of MI's key causal model. J. Consult. Clin. Psychol. 82, 973-983. doi: $10.1037 / \mathrm{a} 0036833$ 
Martin, T., Moyers, T. B., Houck, J. M., Christopher, P. J., and Miller, W. R. (2005). Motivational Interviewing Sequential Code for Observing Process Exchanges (MI-SCOPE) Coder's Manual. Available online at: http://casaa.unm.edu/download/scope.pdf

Matthies, E. (2000). Participatory planning - Considering the further development of a counseling environmental psychology. Umweltpsychologie 4, 84-99.

Miller, W. R., and Johnson, W. R. (2008). A natural language screening measure for motivation to change. Addict. Behav. 33, 1177-1182. doi: 10.1016/j.addbeh.2008.04.018

Miller, W. R., Moyers, T. B., Ernst, D., and Amrhein, P. (2008). Manual for the Motivational Interviewing Skill Code (MISC): Version 2.1. Available online at: http://casaa.unm.edu/download/misc.pdf

Miller, W. R., and Rollnick, S. (2013). Motivational Interviewing: Helping people change 3rd Edn. New York, NY: Guilford Press.

Morgenstern, P. (2014). "Measuring changes in energy behaviours in complex nondomestic buildings," in Presented at the European Conference on Behaviour and Energy Efficiency, (Oxford, UK).

Motivational Interviewing Network of Trainers. (2008). Motivational Interviewing: Training for New Trainers. Resources for Trainers. Available online at: http://www.motivationalinterview.org/Documents/TNT_Manual_Nov_08.pdf

Moyers, T. B., Martin, T. B., Christopher, P. J., Houck, J. M., Tonigan, J. S., and Amrhein, P. C. (2007). Client language as a mediator of motivational interviewing efficacy: where is the evidence? Alcohol. Clin. Exp. Res. 31(s3), 40-47s. doi: 10.1111/j.1530-0277.2007.00492.x

Murtagh, N., Nati, M., Headley, W. R., Gatersleben, B., Gluhak, A., Imran, M. A., et al. (2013). Individual energy use and feedback in an office setting: a field trial. Energy Policy 62, 717-728. doi: 10.1016/j.enpol.2013.07.090

Parkes, G. (2014). "Joint industry project on energy efficiency behaviour change," Presented at the European Conference on Behaviour and Energy Efficiency, (Oxford, UK).
Paulsen, H. F. K., Klonek, F. E., Rutsch, F., and Kauffeld, S. (2015). Ready, steady, go! Veränderungsbereitschaft in der Interaktion messen [Ready, steady, go! Measuring readiness to change in interactions]. PERSONALquarterly, 2, 22-27.

Piderit, S. K. (2000). Rethinking resistance and recognizing ambivalence: a multidimensional view of attitudes toward an organizational change. Acad. Manag. Rev. 25, 783-794. doi:10.2307/259206

Rubak, S., Sandbæk, A., Lauritzen, T., and Christensen, B. (2005). Motivational interviewing: a systematic review and meta-analysis. Br. J. Gen. Pract. 55, 305-312.

Schäfer, S. (2014). "Intervention strategies and behavioural change at the workplace," Presented at the European Conference on Behaviour and Energy Efficiency, (Oxford, UK).

Steiner, S., Diehl, B., Engeser, S., and Kehr, H. M. (2011). Sustainable innovations through user integration: implications for optimization of addressing users and designing innovation workshops. Umweltpsychologie 15, 52-70.

Tharan, A. (2014). "Climate protection by improved energy user behaviour at Eurpoean schools and public buildings," Presented at the European Conference on Behaviour and Energy Efficiency, (Oxford, UK).

Conflict of Interest Statement: The authors declare that the research was conducted in the absence of any commercial or financial relationships that could be construed as a potential conflict of interest.

Copyright () 2015 Klonek and Kauffeld. This is an open-access article distributed under the terms of the Creative Commons Attribution License (CC BY). The use, distribution or reproduction in other forums is permitted, provided the original author(s) or licensor are credited and that the original publication in this journal is cited, in accordance with accepted academic practice. No use, distribution or reproduction is permitted which does not comply with these terms. 